\title{
PROLIFERAÇÃO DE INVENÇÕES EM ESPAÇOS CIRCUNSCRITOS*
}

\author{
Luciana Salazar Salgado ${ }^{1}$
}

Nesta altura, acho que muito do que vou dizer já foi dito de muitos modos, sobre os dispositivos digitais e suas "participações" na produção de sentidos.

Então, considerando que farei uma fala de retomada, eu não queria deixar de dizer que já passou este dia todo de reflexão conjunta, que, certamente, estamos cansados, mas, ainda, estamos intensamente indignados com todas as questões que fizeram da abertura desta jornada também um ato político - e que estão reiteradas nesta mesa, na minha opinião. É muito importante o que fizemos o dia todo: estudar do modo como estudamos. Como é que estão fazendo um monte de ações para matar isto ${ }^{2}$ ? Temos que reagir mesmo, muito fortemente! Fica registrada mais uma vez nossa posição. Também queria agradecer rapidamente, mas profundamente, pela oportunidade de estar de novo com este grupo interdisciplinar, que permite que eu saia do planeta cerrado onde trabalho habitualmente. Isso é muito estimulante e confortante.

Dito isso, explico que o título Proliferação de invenções em espaços circunscritos, que está entre aspas e tem a ver, inclusive, com o seminário que fizemos aqui, também, o Plural da Cultura³ ${ }^{3}$ é uma definição de cultura. Quer dizer, eu penso que é uma definição que De Certeau não propôs

*DOI- 10.29388/978-65-86678-33-8-0-f.81-96

${ }^{1}$ SALGADO, L. S. Discursos e culturas digitais. 2018 (34m19s). Youtube. Disponível em: <https://www.youtube.com/watch?v=IVCskZriblM $>$. Acesso em: 10 out. 2020.

${ }^{2}$ Referência ao suicídio do ex-reitor da Universidade Federal de Santa Catarina e das conduções coercitivas e outras formas de censura e intervenção que se iniciaram em 2017, ferindo sistematicamente a autonomia das universidades públicas federais.

${ }^{3}$ Referência ao Seminário Plural da Cultura - em torno da obra de Michel de Certeau, ocorrido na UFSCar, Campus Sorocaba, em 19 de setembro de 2017 (cf. http://www.cchb.ufscar.br/noticias/seminario-aborda-a-cultura-a-partir-da-obra-demichel-de-certeau e https://grupopesquisacomunica.wordpress.com/labeppe/pluralda-cultura-seminario) 
como tal, mas que se desenha em um dado momento nas suas análises de uma série de circunstâncias delineadas a partir de Maio de 68. Ele conclui que, sendo todos os aspectos que aborda da ordem da cultura $^{4}$, essa coisa difícil de definir - como é o caso de discurso, porque são palavras muito usadas em muitas áreas etc. - trata-se de entender que há movimento, expansão, mas também há restrições, coerção, injunção, e aí chegamos a uma definição que parece muito produtiva: a cultura reunindo tudo que é proliferação de invenções em espaços circunscritos.

Para prosseguir, eu queria fazer um comentário inicial, de apoio ao raciocínio, e peço licença aos colegas de mesa, especialistas, para ser um tanto ligeira neste encaminhamento... O que quero registrar como apoio do raciocínio que proporei é: o que é uma abordagem discursiva? (abordagem prevista para esta mesa). Como disse, serei um pouco ligeira, penso que a proposta da interdisciplinaridade pede isso. Temos de considerar todas as coisas que já apareceram nas reflexões de hoje, mas agora numa conjunção de duas delas, basicamente: uma abordagem discursiva está interessada em saber como é que os sentidos se produzem e, então, como é que as coisas fazem sentido, afinal; evidentemente, há vertentes diferentes de estudo, mas, em linhas gerais, é possível dizer que a produção de sentidos está ligada à relação da língua com uma institucionalidade.

Passo brevemente sobre essas duas coisas - língua e institucionalidade. Antes de mais nada, preciso dizer que um código linguageiro tem a ver com usos, porque, se fosse só um código, os tradutores automáticos funcionariam super bem, seria ótimo (no sentido técnico do termo: eficiente e eficaz, sem perdas), mas não funciona assim, não é? Por mais que se aprimorem os tradutores, mesmo quando tem lá um interpretante razoáveĺ, fornecendo informações e fazendo ajustes. A língua é um código lingua-

\footnotetext{
${ }^{4}$ Os ensaios reunidos na obra, A cultura no plural, publicada como livro em 1974, foram produzidos como reflexões sobre ação cultural, subsidiadas por experiências práticas de planejamento e gestão do historiador francês e por sua pesquisa desenvolvida sobretudo na revista Études, onde publicou diversos artigos sobre os acontecimentos de Maio de 68. Num amplo leque de temas, são abordadas questões relativas a minorias; a aspectos identitários como os linguísticos; à educação básica e à universidade; à cultura de massas e às políticas de gestão da informação; às formas organizacionais de produção de imaginários e valores estéticos.

${ }^{5}$ Referência a conceito abordado durante a jornada, que designa o sujeito de inteligência não artificial, capaz de lidar com as idiossincrasias do vivido.
} 
geiro, significa que ela tem uma dimensão de opacidade, ela não é transparente, não é um código transparente, que se codifica e se decodifica ou se recodifica sem consequências desviantes, digamos, e isso tem a ver com o fato de os sentidos nas línguas se estabelecerem em relações parafrásticas em que, permitam-me, ainda, uma vez ser ligeira, o sentido de uma palavra é sempre outra palavra - e isso pode ser infinito: o sentido de uma palavra é a circunscrição que outras palavras dão a ela em uma dada condição de aparecimento. Estou falando isso porque a gente foi vendo, ao longo do dia, como essas novas técnicas e tecnologias que apareceram não têm nada de óbvias, transparentes e tranquilas. Pois isso acontece com a língua também: a língua é um desses objetos acadêmicos muito maltratados porque, em geral, ela é muito naturalizada, todo mundo fala que lingua é língua, língua é isso que falamos, mas quando chegamos perto e vemos como funciona uma língua, o que produz esse código linguageiro, chegamos a uma complexidade parecida com a "mandala" que o João mostrou, conforme o Geraldo a batizou ${ }^{6}$.

Vejam, a disputa pelo sentido de uma palavra é a disputa por uma descrição do real. Por isso é tão importante decidir o nome das coisas, e das crianças e dos bichos... E isso já nos empurrou para uma noção de institucionalidade, pois, se eu estou falando de uso, se eu estou falando de uma coisa que não é transparente e da necessidade de se estabelecerem relações para "fazer sentido", que sentido é esse que está ecoando aí, então? Tem a ver sempre com uma instituição discursiva, e aqui de novo eu sou ligeira, perdoem, mas acho importante dizer que uma instituição discursiva pode ser uma universidade, um hospital, um governo, mas pode ser também a homofobia, o feminismo, ou seja, não precisa ter um prédio e um regulamento para ser uma instituição, tem a ver com práticas reiteradas que vão funcionando como cerco dos sentidos. O que tem a ver com a história e com a sociedade e tem a ver com o espaço. Essa questão já foi posta no centro hoje $\mathrm{e}^{7}$, e me parece que a noção de território é absolutamente crucial, penso que precisamos dar conta de como é

\footnotetext{
${ }^{6}$ Referência ao diálogo estabelecido pelo Prof. Dr. Geraldo Tadeu Souza (UFSCar) com a apresentação do Prof. Dr. João Maricatto (UnB).

${ }^{7}$ Referência à apresentação feita pelo Prof. Dr. Renato Miguel do Carmo (ISCTE Portugal).
} 
que essa experiência de tempo que a gente tem é produzida pelo espaço, no espaço.

Não vou entrar nisso agora, se for o caso, conversamos depois, quando abrirmos para o público, mas sublinho que é muito importante porque, do ponto de vista do discurso, essa noção interessa no que concerne aos fluxos de texto. Especialmente com a atual aceleração dos fluxos de texto e com as novas qualidades textuais que se formulam, esse problema do espaço demanda estudar o quadro da administração das crenças subordinando os modos de enunciação, as instâncias enunciadoras: o modo como eu digo uma coisa é tão ou mais importante do que a coisa dita, na medida em que o modo é também um o quê, na medida em que preciso, na dimensão dos problemas que apareceram aqui, nesta jornada, entendê-lo no jogo das instâncias enunciadoras, das instituições que produzem textos e os fazem circular.

Nessa perspectiva, considerando a pesquisa sobre cultura, sobre objetos culturais... não sei se já provoquei o suficiente: o que cada um aqui responderia que é cultura? O que é um objeto cultural? Cultura é uma palavra que fazemos de conta ser transparente, tranquila, mas, quando assumimos que é um termo opaco e vamos pensar nele no âmbito do digital, chegamos à ideia de que é preciso pensar que existe uma cibercultura e existe uma cultura digital. Não sei se existem outras coisas também, mas esses grandes blocos são verificáveis, creio. Vou mostrar um caso.

Não sei se eu vou conseguir provar esse entendimento, mas a ideia fundamental é que o digital tem a ver muito fortemente com o padrão - se não houver os protocolos, não existe a noção do digital, isso é importantíssimo: tudo começa na padronização, na conversa entre padrões etc., a própria aceleração dos fluxos tem a ver com protocolos ágeis que permitem padronizar as coisas mais diferentes etc. Assim, no que tange à cibercultura, provavelmente esse padrão tem a ver com uma função fundamental de seletividade. Não sei se todo mundo conhece esse prefixo ciber, ele tem a ver com uma tradição dentro da cibernética, que nasce com o desenvolvimento dos sistemas de controle, não são nem necessariamente digitais. Mas o universo digital é fortemente desenvolvido por causa da cibernética, para atender às necessidades dos sistemas de controle, então, num mundo digital, a cibercultura estaria ligada ao pa- 
drão como seletividade, como controle da distribuição. E aí a ideia de funcionamento em rede parece interessante, a ideia de cultura digital vem do entendimento de que o padrão teria a ver com propagabilidade. Frise-se: não são culturas completamente distintas essas, são nuances semânticas que conduzem, do ponto de vista político, a lugares distintos. O padrão, na cultura digital, teria a ver, fundamentalmente, com a propagabilidade, mas claro que continua havendo seletividade, claro que a seletividade se propaga, em todo caso, como semântica fundamental. Assim, a cultura digital se define na partilha, no estado de conexão, não tem foco na exclusão do diferente ou na domesticação do incerto.

E aí uma metodologia que caiu em desuso, mas que eu acho que seria produtivo retomar nas ciências humanas e sociais. Supõe que se trata, mais do que de rede, de galáxias, porque uma galáxia é tão sistêmica quanto uma rede, mas ela contempla a ideia de relações de forças distintas entre corpos de distinta potência. McLuhan propôs isso, entre outros. Mas como foi meio banido e aí, junto com ele, coisas interessantes foram banidas também, perdeu-se a ideia de galáxia como método de reflexão sobre um sistema, que permite pensar corpos de tamanhos diferentes, forças gravitacionais distintas, com uma dinâmica em que alguns deles desaparecem ou se fundem, ou aparecem... Enfim, penso que isso tem mais a ver com a cultura digital, que estaria mais baseada no que se costuma chamar na historiografia da internet de cultura hacker, a dos primeiros momentos. Se consideramos, então, essa diferença entre cibercultura e cultura digital, podemos ver uma tensão no modo de apropriação das tecnologias: pela ênfase na seletividade ou na propagabilidade.

$\mathrm{E}$, neste momento, eu quero, então, contar o tal caso para vocês, para tirar algumas conclusões, levantar alguns pontos a respeito desse entendimento do mundo digital. O caso é o seguinte: em 14 de junho de 2014, no dia seguinte à abertura da Copa do Mundo no Itaquerão, o jornal Folha de S. Paulo, esse jornal que, na minha opinião, só continua existindo porque os analistas do discurso assinam para fazer seus trabalhos (acho mesmo! É um pouco piada e um pouco não é). Enfim, a Folha de $S$. Paulo publica uma nota, que eu não vou ler na íntegra, porque eu me ocupei, aqui, de recuperar a totalidade gráfica da página. Isso é o que estou tentando resgatar, uma totalidade em funcionamento na qual se estabele- 
cem relações parafrásticas... Em todo caso, vejam que essa página não é mais recuperável ipsis litteris em um buscador - o que nos põe de volta diante de questões que já apareceram durante nosso dia de trabalho: esse mundo digital tem uma imensa perecibilidade, uma efemeridade peculiar, por isso não consegui recuperar tal e qual a página do dia 14. Há conteúdos atuais que convivem com conteúdos daquele dia.

Mas, então, tem lá uma curtíssima reportagem sobre as vaias dirigidas à então presidenta Dilma Rousseff. Não tem título, está registrada a data e também que foi postada às duas da manhã. Logo ao lado desses breves parágrafos, figura um poema do concretista Augusto de Campos com uma explicação - uma legenda: "o poema Viva Vaia é de autoria de Augusto de Campos e foi publicado em 1979 em coletânea homônima de poemas no contexto das discussões do concretismo brasileiro".

"Viva Vaia" é um poema que suscita uma questão definidora do concretismo, que eu não vou explorar aqui e tem a ver com a materialidade (por exemplo, o poema foi publicado incorporando a costura da encadernação). Mas nós estamos em 1979, e esse poema foi feito em homenagem à vaia que Caetano Veloso leva no III Festival Internacional da Canção em 68, com É proibido proibir. É, portanto, uma ode à vaia a partir da qual Caetano diz muitas coisas ao público e ao júri, estabelecendo um marco na relação entre artista e auditório. E eu queria chamar a atenção para um aspecto característico do movimento concretista, supondo que vocês tenham, em alguma medida, uma ideia do que seja, pois é um movimento crucial no meio do século $\mathrm{XX}$, todo o design, toda a teoria do design se valeu muito do que produziram os concretistas, e uma coisa crucial desse movimento estético, no que diz respeito especificamente à poesia - e está lá no Plano-piloto para Poesia Concreta em relevo - é o fato de que o poema objeto, a poesia como um objeto em circulação, se desligava de sua autoria para ganhar o mundo em variadas formas de retomada - esse é um princípio do manifesto concretista.

Vejamos, por exemplo, essa retomada, que foi capa de disco já e aparece em outros lugares, talvez vocês até já tenham visto uma das retomadas e não sabiam que era o "Viva Vaia" do Augusto de Campos".

\footnotetext{
${ }^{8}$ Referência a uma sequência de imagens que mostram retomadas do poema, com variações plásticas importantes. Parte dessa sequência pode ser encontrada no artigo
} 
Essas retomadas vão acontecendo por muito tempo no site do próprio poeta, esse bordado do portal que é a cabeça do site (em vermelho e branco) está agora em amarelo e azul (amarelo clarinho e azul clarinho, não aquele amarelo e azul tucano...). Foi por um tempo retomado nos relógios urbanos, no projeto Arte no Relógio na cidade de São Paulo. Recentemente, talvez entusiasmada com o episódio da Copa do Mundo, uma grife de roupas femininas chamada "Ilumiô" fez uma camiseta - eu não vou ler a matéria de moda para vocês - mas se registre que foi lançada com relativo apelo à polêmica que eu quero mostrar. Diante disso, o elemento disparador do que quero mostrar: Augusto de Campos ficou muito chateado e escreveu para o jornal registrando seu desacordo com o uso do poema, e foi publicado nesta página - o Painel do Leitor. $\mathrm{Na}$ verdade, o texto dele está no que seria uma "segunda página" desse Painel, exige que se role bastante a tela, e aparece com um título dado pelo jornal, porque os jornais habitualmente titulam as cartas de leitores que publicam [Título atribuído pelo jornal: "Xingamentos a Dilma”].

Então o texto de Campos, que aparece assinado por um "poeta e advogado”, está publicado no meio do Painel do Leitor, em meio a outros textos de outros leitores sobre outros temas, só na versão digital, disponível para assinantes. É preciso querer ir até Painel do Leitor e perscrutá-lo para encontrar lá, entre outras, a reclamação desse Augusto. Nesta altura, penso que é o caso de ler o que mais tarde será referido nas redes sociais como "a carta" dele.

\section{"Prezados Senhores,}

Esse jornal utilizou, em 14 de junho de 2014, com grande destaque, o poema VIVA VALA, de minha autoria, como ilustração de matéria ambigua sobre os insultos recebidos pela presidente Dilma, na partida inicial da seleção. Utilizou-o sem minha autorização e sem pagar direitos autorais: sem me dar a minima satisfação. Poupo-me de comentar a insólita atitude da Folha, a quem en poderia processar, se quisesse, pelo uso indevido de texto de minha autoria. A matéria publicada, composta de três artigos e do men poema, cercado de le-

intitulado "Sobre a produção de valor: a recente circulação do poema "Viva Vaia", de Augusto de Campos, disponível em:

< http://periodicos.unb.br/index.php/estudos/article/view/17224>, no qual se desenvolve uma outra abordagem desse mesmo material. 
gendas sensacionalistas, deixa dúvidas sobre a validade dos xingamentos da torcida, ainda que majoritariamente os condene, e por tabela me envolve nessa forjada querela.

A brutalidade da conduta de alguns torcedores, que configura até crime de injúria, mereceria pronta e incisiva condenação e não dubitativa cobertura, abonada por um poema meu publicado fora de contexto.

Os xingamentos, procedentes da área vip, onde se situa gente abastada e conservadora, evidenciam apenas a boçalidade e a truculência que é o reverso da medatha do nosso futebol, assim como a inferioridade civilizatória do brasileiro em relaça a as outros povos.

Escreveu, certa vez, Fernando Pessoa: "a estupidez achou sempre o que quis". Como se viu, até os candidatos de oposição tiveram a desfaçatez de se rejubilarem com os palavrões espúrios.

Pois en thes digo: VIVA DILMA. VALA AOS VIPS."

Augusto de Campos

\section{Comento:}

"A Folha utilizou meu poema VIVA VAIA como ilustração de texto ambíguo sobre os insultos recebidos pela presidente Dilma. Utilizou-o sem minha autorização, sem pagar direitos autorais..." Vejam que interessante, ele é signatário do Manifesto que diz que o poema se desprende do autor. Muito interessante isso! "Sem me dar a mínima satisfação", "Poupo-me de comentar a insólita atitude do jornal ao qual eu poderia processar pelo uso indevido de texto de minha autoria”... É muito interessante isso, porque, do ponto de vista estético, não faz nenhum sentido ele reivindicar essa autoria, do ponto de vista político, sim. O cidadão, que é também poeta (ou o poeta, que é também cidadão) não aceita essa retomada.

"A reportagem em que o meu poema é cercado de legendas sensacionalistas deixa dúvida sobre a validade dos xingamentos da torcida e por tabela me envolve nessa forjada querela", "a brutalidade da conduta de alguns torcedores mereceria incisiva condenação e não dubitativa cobertura abonada por um poema meu publicado fora de contexto"... Esse "fora de contexto", para um concretista, é louquíssimo. A ideia não era a 
de que o poema vai para o mundo para ser retomado em variações plásticas...? Mas a hipótese explicativa é: o lugar de fala se altera aqui, não é o poeta signatário apenas, é o consagrado poeta do panteão da cultura brasileira que emite opinião sobre as coisas deste país e que está claramente se sentido convocado a um posicionamento que não é o dele, e assume vigorosamente o seu: "os xingamentos proferidos pela área vip do estádio, onde se situa gente abastada e conservadora, evidenciam a boçalidade e a truculência que é o reverso da medalha do nosso futebol, assim como a inferioridade civilizatória do brasileiro", "até os candidatos de oposição tiveram a desfaçatez de se rejubilarem com os palavrões espúrios"... E, depois dessa denúncia de caráter moral, ele deixa, em uma linha, em destaque: "Pois eu lhes digo: VIVA DILMA, VALA AOS VIPS. Nesses termos, Viva se separa de Vaia, o primeiro saúda à presidenta injuriada; o segundo joga sobre o público truculento uma vaia que retoma a que recebeu Caetano no Festival, aquela que a história mostraria ser um marco definidor tanto do grande artista quanto do público xucro, movido pelo regime de exceção em franca implantação no período.

Houve discussão, em alguns fóruns, sobre ele haver criado um novo poema. Há toda uma questão da aliteração da letra $\mathrm{V}$, também da sua força gráfica - VIVA DILMA. VAIA AO VIPS. Houve também muita discussão sobre o fato de um poema ser usado como ilustração, no caso da reportagem publicada pelo referido jornal. Do ponto de vista estético, isso já é uma questão enorme. Mas o que eu quero mostrar para vocês é que, no dia seguinte às vaias no Itaquerão - dia 15, portanto - a carta sai publicada naquele lugar que eu mostrei, e o próprio Augusto de Campos vaza seu texto na internet, vaza-o pedindo circulação.

Apresenta-se como o ponto inicial do vazamento a postagem de Glauco Cortez. Vejam que interessante, ele faz a mesma coisa que o jornal: dá um título para o texto. Afinal, na "blogosfera" é assim que são feitas essas chamadas, as repostagens, as apropriações, as redes: "Augusto de Campos destrói a Folha de S. Paulo, "VIVA DILMA, VAIA AOS VIPS" - isto é o que vai aparecer nos buscadores, e aí, já na página aberta, encontra-se a explicação de que o texto foi publicado a pedido do próprio Augusto de Campos: "Publicando, a pedido de Augusto de Campos, carta ao jornal Folha de S. Paulo". 
Gostaria de chamar a atenção para os botões que há nesta página, pois estamos falando da propagabilidade, e vejam o número de possibilidades de "repassagem" que essa estrutura oferece (há onze botões para aplicativos ou plataformas). Essas coisas não são bichinhos que estão aí enfeitando o layout, tudo isso são formas de produzir fluxo de textos em comunidades distintas. Enfim, importa aqui constatar que esse texto, com distintas chamadas (portanto, distintos enquadramentos de leitura) se espalhou loucamente. Em três dias, a quantidade de resultados que se obtinha pesquisando em máquinas diferentes, não só no meu note, que já estava atrás desse tema, era daquela ordem dos zilhares, quando nem guardamos mais os números, aquela quantidade que dá uma sensação de "viralizou”, "bombou", "explodiu”. Sobre isso, só mais uma observação: foi explodindo - e é isso que eu tenho para mostrar para vocês - numa dada direção semântica. Vejam como aparecia: "Augusto de Campos [um verbo: detona, destrói, arrasa...] a Folha, que não publicou"; "Augusto de Campos critica uso de poema”; “ 'Viva Dilma, vaia aos vips', diz poeta Augusto de Campos"... É muito interessante ver como a mesma coisa não é mais a mesma coisa, os modos como a "carta" vai sendo retomada vão construindo novos sentidos, que se coadunam e produzem um certo rumor público. Com o passar dos dias, uma semântica começa a predominar: ele destrói, ele acaba com, ele botou no bolso, palavrões... essa é a semântica que se intensifica no decorrer dos dias, uma torcida animosa que lembra a de futebol.

Foi possivelmente esse rumor público que levou o jornal a republicar a carta três dias depois. Três dias depois. Tudo isso em três dias! O jornal republica a carta no Painel do Leitor de novo, mas agora em destaque, logo na abertura do Painel, tanto no jornal impresso quanto no digital, na parte aberta do digital. Claro que o texto, mesmo aí, está competindo como uma quantidade de coisas que se movem, oferecendo produtos e serviços, tem pop-ups, tem de tudo aí nessa página tremendamente comercializada do jornal. E vejam que a carta que eu li para vocês é republicada com este título: "Augusto de Campos critica uso de poema em reportagem sobre vaias”. Essa é uma questão muito cara para a análise do discurso: eu estou falando do mesmo texto ainda? Mesmo, mesmo? O mesmíssimo? Vejam a quantidade de sentidos que se foram acumulando 
nessa circulação ora selecionada e controlada pelo jornal que a tranca no Painel do Leitor, onde logo perecerá sem muitas visualizações, ora propagada sem controle da diversidade de enquadramentos. Me interessa observar o modo como esse texto se espraia.

Por exemplo: o livro VIVA VAIA ${ }^{9}$ apareceu inclusive no Skoob $^{10}$, e é interessante que, vendo as anotações das pessoas sobre esse livro de 1979, constata-se que muita gente que começa a aparecer na plataforma tem alguma coisa a dizer sobre o livro. Ele é postado nessa conjuntura (e não antes...), e a comunidade começa a dizer que o livro é bacana etc. No final de 2015, esse livro é republicado, e devo comentar alguns pontos notáveis: o poema Viva Vaia, que era preto no fundo branco da página em 1979, aparece agora em vermelho. A semiótica das cores está posta na conjuntura, marcando o embate entre "vermelhos" e "verde-amarelo seleção canarinho". Há também um CD em que o filho de Augusto de Campos, Cid, trabalhou sonoridades. Em 79 não havia essa mídia e, de fato, nenhuma correlata em termos editoriais. É ainda o mesmo livro? O mesmo poema? Sua constituição institucional mudou, é um dado. Sua constituição material também, outro dado.

Em julho de 2016, houve no Sesc Pompéia, em São Paulo, na sua imensa área de convivência, aberta a quaisquer passantes, uma exposição de "obras completas", digamos, de vida inteira". Sobre isso, queria chamar a atenção - porque também o acho um elemento complicador para o fato de estarmos acostumados a pensar que cibercultura e cultura digital (supondo que tenham aceitado essa divisão que eu propus) estão apenas nos meios digitais, se vivificam apenas pelos dispositivos digitais, mas, em termos de cultura, elas transcendem os dispositivos digitais e se impõem como uma lógica hegemônica também ao que não é digital.

Os livros didáticos me parecem emblemáticos, pois quando se

9 CAMPOS, A. dos. Viva vaia: poesia 1949-1979. São Paulo: Ateliê Editorial, 2014.

${ }^{10}$ Esse nome deriva da palavra books ("livros", em inglês) lida ao contrário; trata-se de uma das maiores redes sociais colaborativa para leitores. Foi lançada em janeiro de 2009 pelo desenvolvedor Lindenberg Moreira, e permite cadastrar livros lidos, que se pretende ler, leituras abandonadas e títulos desejados, de modo a criar uma biblioteca definidora de um perfil. Os usuários também podem trocar livros por meio do "Skoob Plus".

${ }^{11}$ Referência à exposição "REVER_Augusto de Campos", com curadoria de Daniel Rangel. De 5 de maio a 31 de julho de 2016 no Sesc Pompeia, São Paulo. 
abre um livro didático impresso, logo se vê o hipertexto característico: a estética da navegação está ali emulada, a lógica que preside sua produção é a da cibercultura - ou de uma cultura digital, na hipótese de um livro que busca diversidade, pluralidade e não sobretudo uma padronização conceitual. Considerando isso, o que eu queria sublinhar sobre essa exposição é que se tratava de uma exposição de vida inteira, grande, em que havia um percurso espacialmente sugerido; e o poema Viva Vaia, vejam como ele aparece nessa exposição: é uma obra imensa de ferro vermelho, instalada na saída do percurso sugerido. E, para o que interessa aqui hoje, vale dizer que essa exposição estava abarrotada de "bedéis". Era uma equipe muito grande tomando conta mais dos passantes do que das obras (muitas delas com equipamentos como vídeo e som), porque, entre outras justificativas, temia-se vandalismo. Havia um receio de que a exposição fosse atacada, porque o Augusto de Campos começou a aparecer de novo, deu entrevistas, etc. E vale frisar a própria decisão do SESC de fazer essa exposição, essa curadoria, a qual também configurava, naquele momento, um engajamento na conjuntura que se produziu.

Vejam que existem questões de seletividade e questões de propagabilidade que estão operando em momentos diferentes dessa história: o primeiro texto de Augusto de Campos estava na internet trancado, apagado, desaparecido, impedido de circular, isso fica óbvio para nós depois da discussão deste dia inteiro juntos, mas, em geral, não é o que se crê. Costuma-se pensar que tudo que é digital vai para todos, é aberto, está ali, de modo que a questão é aprender a achar.

Voltamos, então, ao aspecto ciber do acontecimento: a internet pode travar coisas, não permitir que circulem (ou permitir que não circulem...). Isso é muito importante na discussão sobre neutralidade da rede, sobre o modo como funcionam os provedores, as chamadas cidades inteligentes... Onde estão os sinais? Esses sinais permitem acessar que tipo de coisa? A neutralidade da rede é o tópico em que mais evidentemente isso aparece: existem formas de seletividade que podem transformar a internet no lugar mais eficaz em termos de impedimento da circulação, o que vai na contramão de um certo senso comum, como vemos. É interessante ver que o poeta, diante disso, sabe que, no âmbito da "blogosfera", é a propagabilidade que predomina como semântica fundamental, 
então, ele aposta que ali todo mundo vai repassar, vai acrescentar suas posições, e isso vai sair do controle em que se pretendeu trancar o texto.

Infelizmente, eu não guardei alguns screenshots. Numa dessas limpezas de máquina, que não está aguentando mais o tranco, perdi material - as questões de metodologia incluem essas práticas e essas necessidades, não é? - e eu não consegui recuperar boa parte dos espaços que "reblogaram" isso na época. O material viralizou, mas essa viralização depois desapareceu... Vejam só.

Enfim, me parece que essa divisão é produtiva para entender esse tipo de acontecimento. E, defendendo-a, faço algumas considerações finais, que talvez até pareçam um pouco apressadas.

Esta questão que apareceu aqui desde a manhã, mas sempre de modo muito lateral, acho que Dalton talvez tenha sido mais explícito sobre a experiência de aceleração ${ }^{12}$, no sentido daquele sentimento angustiante que todos temos relativo à quantidade de coisas que nos chegam e que temos de administrar, de demandas por ação. Para nós das ciências humanas e sociais, é muito importante pensar o tempo, e o tempo como uma categoria do espaço, nesse lugar onde estamos organizados - nós e os nossos objetos.

O celular, por exemplo, é um superacelerador de tempo: estamos simultaneamente em um monte de lugares quando portamos um celular. Todos nós estivemos aqui hoje e em muitos outros lugares o dia inteiro. Do ponto de vista cognitivo, isso é muito relevante, porque isso dá certos cansaços, traz certas dificuldades... e aí a máquina nos vence.

Outra coisa que apareceu aqui e que me parece digna de nota é como isso tem a ver com bolhas e ilhas. Não me estendo sobre o tópico, porque parece evidente, agora, com todas as discussões que nós tivemos; mas eu queria chamar a atenção para o fato de que, possivelmente, muitos aqui não se lembravam dessa história que aconteceu em 2014, nem da sensação enquanto ela estava acontecendo naqueles quatro, cinco dias.

Recentemente, eu estava numa oficina, em um congresso, e aí as pessoas comentavam a surpresa diante desses dados, tinha gente que não lembrava nem das vaias no Itaquerão! Ou seja, tem uma questão importante que é: viralizou e bombou para quem? Em que mundo? Em que

\footnotetext{
${ }^{12}$ Referência à fala do prof. Dr. Dalton Martins (UFG).
} 
jardins? Somos levados de volta àquele problema dos números: como eu coleto os números que atestam a existência do acontecimento? Para fazer o quê com eles? Porque, em análise do discurso, está cada vez mais comum fazer um comentário elegante e inteligente, na melhor das hipóteses, a partir de um conjunto de coisas coletadas por aí e pronto. Mas onde? Na "internet"? No "Google"?, como se diz muitas vezes.

Estamos falando de pesquisa acadêmica, em que isso é perigosíssimo, porque mostra um desconhecimento de um tamanho! E um nível de distorção a que chegam as pesquisas... Em termos de produção dos sentidos, não se consegue explicar o que está acontecendo socialmente, como é que certos discursos se hegemonizam e outros perecem. Não se pode entender isso. Se se fala "peguei no Google", ignora-se a natureza básica da máquina, que tem toda uma programação que o próprio uso vai produzindo etc.

Isso nos leva a uma outra questão que também me parece crucial para as humanidades hoje, que é trabalhar com o que, no meu planeta, tem se chamado de materialidades inscricionais; essa ideia de que as materialidades inscricionais têm valor discursivo, ou seja, não é o texto do Augusto de Campos, é um conjunto de inscrições do "mesmo texto" que produz seu valor: ele vale como objeto editorial, objeto de cultura. Tratase desse entendimento de que a nossa relação com os objetos é subjetivante. Exemplo breve: tem o celular, você compra e começa a dar um monte de informação para ele; depois de um tempo, é ele que começa a dar um monte de informação para você, inclusive a hora que tem que buscar o filho, quando tem que pagar a prestação da casa... Ele começa a dizer o que é que você vai fazer agora. Os objetos de cultura são, hoje, altamente subjetivantes. Se eu não descrever as materialidades, os objetos que nos organizam...

Que tipo de cadeiras são estas? Vejam, não temos como ficar em círculo nesta sala. Nada disso é neutro, tudo isso é portador de discursividade em alguma medida. Parece-me, então, que a descrição das materialidades inscricionais, e aí o digital nos põe um problema interessante, não tem ainda metalinguagem adequada. Ainda não desenvolvemos uma 
metalinguagem. Um exemplo breve, típico: no nosso grupo de pesqui$\mathrm{sa}^{13}$, temos dificuldades técnicas porque não está clara a diferença entre um site e um blog.

Percebemos que a definição vem muito das autorrepresentações, porque, do ponto de vista técnico, tem coisa que parece site mas chama blog. Daí a pergunta que eu fiz para o Dalton no final da manhã. Pareceme que temos que assumir uma descrição minuciosa das coletas, inclusive dos momentos de coleta que não dão certo, que são apenas especulativos, porque, mesmo que eu não saiba direito para quê vai servir aquela minha descrição, certamente ela baliza o trabalho. De algum modo ela pode chegar a uma pergunta de pesquisa inaudita.

Se há distorção nos seus resultados, digamos assim, os outros pesquisadores têm uma pista para compreender que tipo de distorção, a partir de que variável essa distorção se deu, e eu estou falando nisso de novo porque, em muitas das áreas desse grande campo que chamamos aqui de ciências humanas e sociais, isso é bastante opaco e já daria um grande debate. Por exemplo, a linguística não se coloca aí, a linguística é um "império do meio", como diz Bruno Latour ${ }^{14}$, ela está lá no meio de todas as coisas, mas não é nenhuma delas.

Eu encerro estas considerações dizendo que me parece importante que a gente assuma uma atitude propositiva. Já foi falado entre nós hoje, foi faladíssimo o dia inteiro: temos de ter a coragem de ser propositivos. É preciso, por exemplo, criar uma metalinguagem adequada para esses objetos de cultura.

É preciso encontrar uma metalinguagem adequada principalmente para os pontos cegos e cantos mortos, porque também nós temos a tendência a pensar o epicentro dos fenômenos, e parece que nas periferias, nos indícios, nos resíduos é que se vai encontrando um material, do ponto de vista discursivo, muito potente para explicar essas coisas que têm nos deixado um tanto perplexos. Precisamos tratar dessa prolifera-

\footnotetext{
${ }^{13}$ Referência ao Grupo de Pesquisa Comunica - inscrições linguísticas na comunicação. (cf. Disponível em: <https://grupopesquisacomunica.wordpress.com>. Acesso em: 10 out. 2020

${ }^{14}$ LATOUR, B. Jamais fomos modernos: ensaio de antropologia simétrica. Trad. Carlos Irineu da Costa. São Paulo: Editora 34, 1994.
} 
ção de invenções compreendendo como se estabelece a circunscrição dos espaços em que ela se torna possível, desejável, inescapável.

Conversamos mais depois, obrigada. 